\title{
SOBRE A NÃO-LINEARIDADE DE FENÔMENOS ACÚSTICOS E O FUNCIONAMENTO DA FLAUTA TRANSVERSA: UMA INCURSÃO PELA ACÚSTICA MUSICAL ${ }^{+*}$
}

Paulo Lima Junior

Luís Gustavo Pires Rodrigues

Maria Teresinha Xavier Silva

Instituto de Física - UFRGS

Porto Alegre - RS

\section{Resumo}

A produção de som com instrumentos musicais constitui um referente fundamental para o ensino de acústica na educação básica e superior. Uma das características dos modelos consagrados no ensino de Física para fenômenos acústicos é que, nestes modelos, tais fenômenos são considerados lineares. Com efeito, pesquisas do campo da acústica musical indicam que, no funcionamento de instrumentos musicais, estão envolvidos processos não-lineares fundamentais sem os quais não se pode compreender o funcionamento desses instrumentos. No presente trabalho, contribuímos para a discussão de fenômenos acústicos no ensino de Física, abordando os limites da hipótese de linearidade em acústica musical a partir de um instrumento especifico: a flauta transversa. Discutimos a equação de onda acústica (equação que governa a propagação de ondas sonoras em fluidos como o ar), destacando os pressupostos que a sustentam e seu domínio de validade. Com ra-

\footnotetext{
Concerning the nonlinearity of acoustics phenomena and the functioning of the transverse flute: an incursion into the musical acoustics

* Recebido: outubro de 2011.

Aceito: abril de 2012.
} 
zão, a validade da equação de onda acústica está intimamente ligada à questão da linearidade de fenômenos acústicos e, por isso, esta equação é tão fundamental para a presente discussão. Enfim, abordamos a técnica de excitação da flauta transversa (chamada embocadura) para encontrar nela uma não-linearidade fundamental implicada no processo de produção de som deste instrumento. Acreditamos que a presente discussão é uma contribuição para o refinamento dos modelos consagrados no tratamento didático de fenômenos acústicos no ensino de Física em Educação Superior.

Palavras-chave: Acústica Musical. Flauta Transversa. Equação de Onda Acústica. Não-linearidade.

\begin{abstract}
Sound production on musical instruments is a fundamental referent for the acoustics teaching in secondary and higher education. One main feature found amid established models for approaching acoustical phenomena in Physics is linearity. Indeed, researches in the field of musical acoustics indicates that most musical instruments involve fundamentally nonlinear processes without which one can not understand the operation of these instruments. In this paper, we contribute to the discussion of acoustical phenomena in teaching Physics, approaching the limits of the hypothesis of linearity in musical acoustics from a specific instrument: the transverse flute. We discuss the acoustic wave equation (the equation that governs the propagation of sound waves in fluids such as air), highlighting the assumptions that underpin this equation and its validity. In fact, the validity of acoustic wave equation is closely related to the question of linearity on acoustical phenomena. Finally, we discuss the technique of excitation of the transverse flute (embouchure) to find it an essential nonlinearity involved in producing sound with this instrument. We believe that this discussion is a contribution to the refinement of the established models in approaching acoustical phenomena in higher education Physics teaching.
\end{abstract}


Keywords: Musical acoustics. Transverse flute. Acoustical wave equation. Nonlinearity.

\section{Introdução}

Embora arte e ciência sejam frequentemente definidas uma em oposição à outra, não é muito difícil apontar interesses e características comuns entre estes dois campos da atividade humana. Por exemplo, a noção de proporção utilizada na antiguidade (e ainda em tempos atuais) na música, pintura, escultura e arquitetura evidencia a relação da arte com a matemática. O número de ouro, ou divina proporção, é derivado de uma relação geométrica e foi utilizado sistematicamente ao longo da história para produzir e avaliar a beleza em obras de artes plásticas (HENRIQUE, 2002).

As relações entre ciência e música, por sua vez, não são poucas. Som e silêncio são a matéria-prima da música e objetos de estudo da Física e da Psicofísica. Uma análise Física do som implica compreendê-lo em seu processo de produção e propagação. Por outro lado, uma análise Psicofísica está relacionada ao processo de recepção do som e à sensação que ele provoca no ouvinte.

A acústica é o ramo da Física que tem por objeto de estudo o som enquanto fenômeno físico. A acústica musical, por sua vez, é um campo multidisciplinar que mobiliza engenheiros, músicos e cientistas (sobretudo físicos) de várias especialidades em torno de estudos da produção, propagação e recepção do som. A acústica musical (enquanto campo de produção de conhecimento aplicado à música) é historicamente recente e consolidou-se ao longo do século XX (HENRIQUE, 2002). Assim, é importante destacar que grande parte dos instrumentos e das técnicas musicais conhecidos hoje foi desenvolvida tentativamente ao longo da história da música e já se encontrava pronta quando do surgimento da acústica musical. Com efeito, para que um músico tire um belo som de um instrumento, não é estritamente necessário saber que notas musicais soam diferentes porque correspondem a vibrações em frequências diferentes. Nem é preciso que o artífice conheça a equação de onda acústica para fabricar um violino de boa sonoridade. Assim, os campos da música e da acústica musical são relativamente independentes porque abordam com propósitos diferentes o mesmo objeto: o som.

Apesar dessa independência relativa, o campo da acústica musical tem contribuições relevantes para a música. $\mathrm{Na}$ medida em que cientistas elaboram modelos confiáveis para os fenômenos acústicos envolvidos no processo de produção e propagação do som, tem sido possível contribuir para (HENRIQUE, 2002): (1) o desenvolvimento de novos materiais e novas técnicas de manufatura de ins- 
trumentos musicais; (2) o aprimoramento das técnicas de execução dos instrumentos musicais; (3) o planejamento de reformas e construções de teatros e salas de concerto.

Além dos seus desdobramentos técnicos e tecnológicos, o campo da acústica musical tem grande potencial de contribuição para o ensino de Física na medida em que permite revisar, criticar e re-elaborar modelos acústicos que, consagrados no ensino de Física, são aplicados frequentemente para explicar o funcionamento dos instrumentos musicais (HALLIDAY et al., 2009; NUSSENZVEIG, 2004; TIPLER; MOSCA, 2009). Uma das características dos modelos mais consagrados da acústica no ensino de Física é que todos eles são lineares (uma evidência disso é que, para todos esses modelos, vale o princípio da superposição) e é justamente em virtude desta linearidade que fenômenos acústicos parecem ser fundamentalmente simples de se compreender. Infelizmente, a hipótese de linearidade nem sempre se sustenta e alguns processos da acústica de instrumentos musicais são fundamentalmente não-lineares (FLETCHER, 1999).

No presente trabalho, contribuímos para a discussão da complexidade de fenômenos acústicos, discutindo os limites da hipótese de linearidade em acústica musical a partir de um instrumento específico: a flauta transversa. Por se tratar de um instrumento de sopro, o funcionamento da flauta transversa está intimamente ligado à dinâmica da coluna de ar no seu corpo. Por esta razão, a equação de onda acústica (equação que governa a propagação de ondas sonoras em fluidos como o ar) é apresentada aqui, destacando seus pressupostos, o que permite discutir o domínio de validade desta equação. A validade da equação de onda acústica está ligada à questão da linearidade dos fenômenos acústicos e, por isso, esta equação é tão fundamental para a presente discussão. Enfim, abordamos a técnica de excitação da flauta transversa (chamada embocadura) para encontrar nela uma nãolinearidade fundamental implicada no processo de produção de som deste instrumento. Acreditamos que a presente discussão é uma contribuição para o refinamento dos modelos consagrados no tratamento didático de fenômenos acústicos no ensino de Física no ensino superior.

\section{A flauta transversa: Primeira aproximação}

A escolha de estudar a flauta transversa deve-se ao fato de ela ser um instrumento de sopro relativamente simples, consistindo de um tubo cilíndrico com um bocal (onde o flautista posiciona os lábios) e diversos orificios laterais que, controlados por um sistema de chaves articuladas, permitem a emissão de som em 
diferentes frequências (Fig. 1). É importante destacar que, na flauta transversa, a extremidade mais próxima do bocal é mantida sempre fechada.

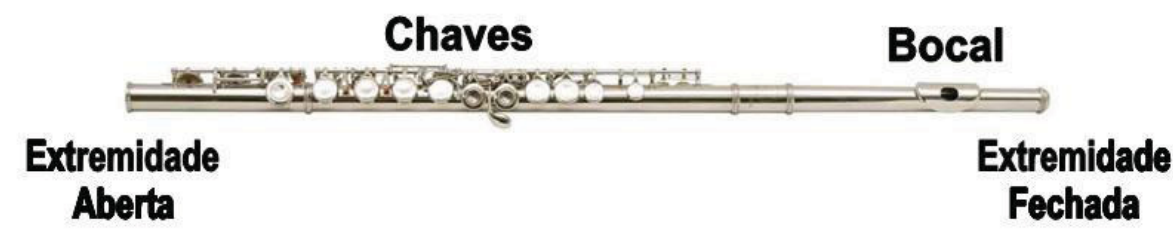

Fig. 1 - Imagem da flauta transversa (ou flauta de Boehm).

Mudando a digitação (posicionamento dos dedos nas chaves que controlam os orifícios laterais) e a embocadura (técnica de sopro e posicionamento dos lábios próximo ao bocal), o flautista pode obter as diversas notas que compõem a escala cromática ${ }^{1}$. A Fig. 2 é um diagrama (chamado pentagrama) que representa a escala cromática.

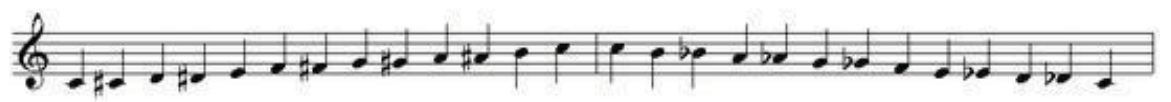

Fig. 2 - Escala cromática crescente e decrescente.

As notas mais altas (ou agudas), representadas nas linhas superiores do pentagrama, correspondem a vibrações de maior frequência. Igualmente, as notas mais graves são registradas nas linhas inferiores do pentagrama e correspondem a vibrações de menor frequência. Todas as notas, ao menos em princípio, são compostas de um modo de vibração fundamental e seus múltiplos inteiros. $\mathrm{O}$ fato de os sistemas acústicos possuírem um conjunto de modos de vibração (também chamados harmônicos) é abordado frequentemente na maioria dos textos introdutórios de acústica e mecânica ondulatória (HALLIDAY et al., 2009; NUSSENZVEIG, 2004; TIPLER; MOSCA, 2009). Entretanto, é preciso reconhecer que a relação entre os diagramas que representam ondas estacionárias e o conceito de nota musical nem sempre é devidamente explicitada nos textos de Física Básica.

${ }^{1}$ Escala cromática é a escala musical mais completa da música ocidental. Ela contém todas
as notas naturais (Dó, Ré, Mi, Fá, Sol, Lá e Si) e acidentais (Dó\#, Ré\#, Fá\#, Sol\# e Lá\#). 


\section{A física das notas e da escala musical}

Uma corda esticada e fixa em suas duas extremidades (como cordas de violão, piano, violino) pode vibrar somente de alguns modos determinados. A Fig. 3 representa os três primeiros modos de vibração (harmônicos) de uma corda esticada. É possível demonstrar que cada harmônico possui uma frequência característica e que a frequência de qualquer um deles é sempre um múltiplo inteiro da frequência do harmônico fundamental. A rigor, quando tocamos o violão (ou outro instrumento de cordas), cada corda vibra de uma maneira relativamente complexa que resulta da superposição dos seus vários harmônicos. Ou seja, cada corda realiza, ao mesmo tempo, um conjunto de modos de vibração, emitindo, portanto, um conjunto de frequências $\left(f_{0}, 2 f_{0}, 3 f_{0}, \ldots\right)$. A propósito, situação análoga a essa em que a corda (de um violão, digamos) emite várias frequências simultaneamente também ocorre em instrumentos de sopro.

Alguns músicos muito habilidosos conseguem dominar seu instrumento ao ponto de fazê-lo emitir somente um harmônico de cada vez. Entretanto, a situação usual é que notas musicais consistam de uma emissão simultânea de várias frequências (sendo todas elas múltiplos de uma frequência fundamental). Como todas as frequências de uma nota musical devem ser múltiplos inteiros da sua frequência fundamental, basta conhecer a frequência fundamental de certa emissão para determinar (do ponto de vista da Física) qual nota está sendo tocada.

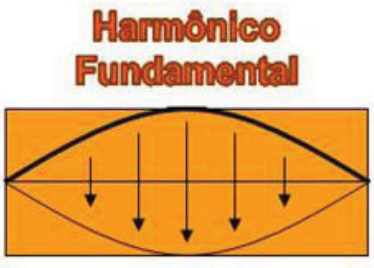

frequência $=f_{0}$

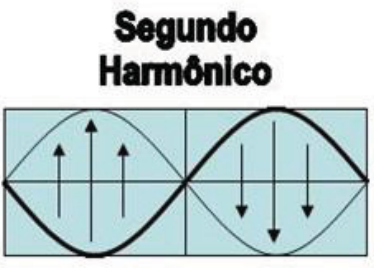

frequência $=2 f_{0}$

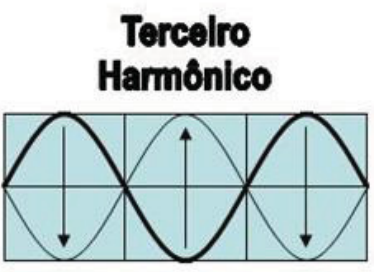

frequência $=3 f_{0}$

Fig. 3 - Os três primeiros harmônicos de uma corda vibrante.

O harmônico fundamental do Lá mais grave que se pode obter com uma flauta transversa possui frequência igual a $440 \mathrm{~Hz}$. Considerando que este Lá corresponde ao terceiro Lá do piano, ele será chamado Lá3. Em qualquer instrumento musical, o Lá3 pode compreender, além da vibração fundamental que caracteriza esta nota, uma superposição de todos os seus múltiplos inteiros: $880 \mathrm{~Hz}, 1320 \mathrm{~Hz}$, 
$1760 \mathrm{~Hz} .$. Assim, embora as notas musicais sejam suficientemente identificadas pela frequência de vibração de seu harmônico fundamental, em geral, todas as notas são compostas por um conjunto de vibrações diferentes realizadas simultaneamente pelo sistema acústico.

Tendo compreendido que uma nota é composta, simultaneamente, por seu harmônico fundamental e seus múltiplos inteiros, convém perguntar: Que sensação se experimenta ao escutar uma nota que tenha seu harmônico fundamental com frequência igual ao dobro do harmônico fundamental de outra nota? Por exemplo, o que sentimos ao ouvir uma nota que tenha seu harmônico fundamental a $880 \mathrm{~Hz}$ ?

Em realidade, embora uma nota soe mais aguda que a outra, é possível identificar que, nos dois casos (notas com $f_{0}$ igual a $440 \mathrm{~Hz}$ e $880 \mathrm{~Hz}$ ), estamos ouvindo o mesmo som! Por isso, se duas notas têm harmônicos fundamentais tais que a frequência de um é igual ao dobro (ou metade) da frequência do outro, elas recebem o mesmo nome. Seguindo essa lógica, chama-se Lá4 a nota que tem seu harmônico fundamental vibrando a $880 \mathrm{~Hz}$ (acompanhado por vibrações a $1760 \mathrm{~Hz}, 2640 \mathrm{~Hz}, 3520 \mathrm{~Hz} .$. ) e Lá5 a nota que tem seu harmônico fundamental em $1760 \mathrm{~Hz}$ (e outras frequências em $3520 \mathrm{~Hz}, 5280 \mathrm{~Hz}, 7040 \mathrm{~Hz} .$. ).

Enfim, chama-se oitava a distância na escala musical entre duas notas que têm o mesmo nome, ou seja, duas notas tais que a frequência fundamental de uma é igual ao dobro (ou metade) da frequência fundamental da outra. A Figura 4 representa aproximadamente o espectro de emissão (intensidade da emissão em função da frequência) de duas notas musicais distantes uma oitava (Lá3 e Lá4).

\section{Digitação e embocadura em instrumentos de sopro}

Uma característica de vários instrumentos de sopro (inclusive a flauta transversa) é de ser possível obter as mesmas notas em diferentes oitavas sem modificar a digitação, alterando-se somente a embocadura. Ou seja, soprando de maneira diferente (mudando sutilmente a posição dos lábios e da mandíbula e alterando a intensidade do sopro), o flautista pode dobrar ou diminuir pela metade a frequência fundamental de vibração do ar dentro do tubo, alterando o som emitido em uma oitava. No Quadro 1, encontra-se a representação esquemática dos orifícios laterais da flauta transversa que, abertos, permitem obter cada uma das notas da escala cromática nas duas primeiras oitavas. 

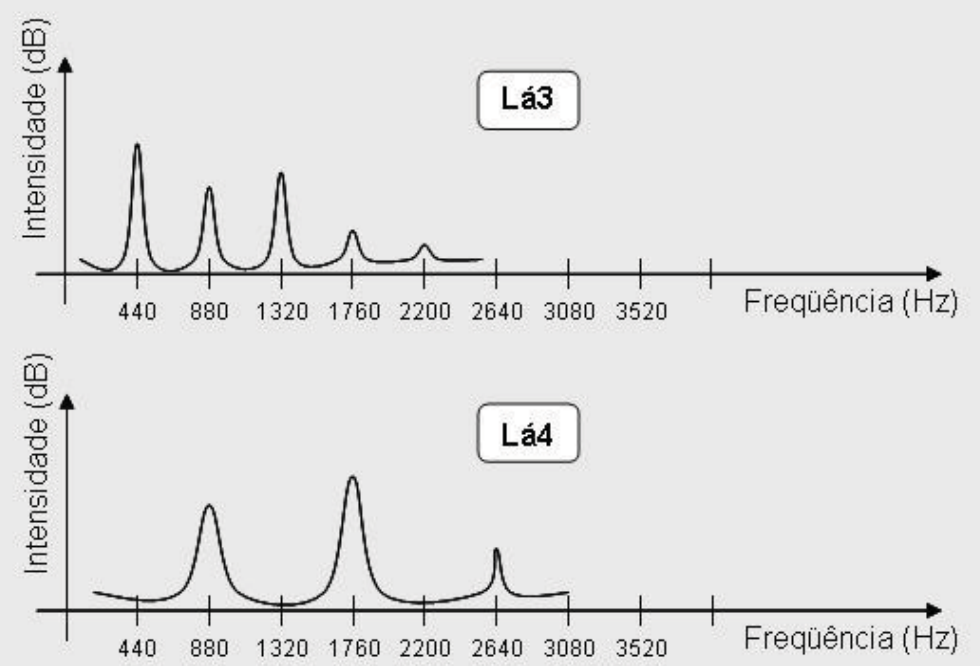

Fig. 4 - Representação esquemática dos espectros de emissão do Lá3 e do Lá4.

Como é possível perceber a partir do Quadro 1, a digitação na flauta transversa é extremamente simples nas duas primeiras oitavas . A transição de uma nota para outra mais aguda na flauta corresponde sempre à abertura progressiva dos seus orifícios laterais. Abrindo e fechando tais orifícios, o flautista encurta e alonga o comprimento efetivo do tubo cilíndrico que constitui a flauta, obtendo as diversas notas musicais.

\section{O problema da embocadura}

A rigor, a acústica dos instrumentos musicais tende a ser bastante complexa, envolvendo diversos fenômenos não-lineares que não podem ser despreza-

\footnotetext{
2 A rigor, o Quadro 1 apresenta as digitações que tornam possível emitir cada uma das notas na escala cromática. Em realidade, por uma questão de sonoridade (beleza do som), e não por uma questão de Física, a maioria dos flautistas realiza uma digitação distinta daquela apresentada no Quadro 1 para as notas Dó4, Dó4\#, Ré4 e Ré4\#. Para efeito da análise realizada neste artigo, esta variação da digitação não tem importância fundamental.
} 
dos se desejamos adquirir uma compreensão apropriada do funcionamento destes instrumentos (FLETCHER, 1999). A embocadura na flauta transversa é um exemplo de fenômeno acústico bastante complexo do ponto de vista da Física.

Quadro 1 - Relação dos orifícios laterais da flauta que, mantidos abertos, permitem executar notas da escala cromática na flauta transversa.

\begin{tabular}{|c|c|c|c|c|}
\hline $\begin{array}{l}\text { la Oitava }^{\text {da Flauta }} \\
\text { da }\end{array}$ & $\begin{array}{c}\text { Harmônico } \\
\text { Fundamental }\end{array}$ & $\begin{array}{l}2^{\mathrm{a}} \text { Oitava } \\
\text { da Flauta }\end{array}$ & $\begin{array}{l}\text { Harmônico } \\
\text { Fundamental }\end{array}$ & $\begin{array}{c}\text { Orificios abertos } \\
\text { (representados em branco) }\end{array}$ \\
\hline Dó3 & $261,6 \mathrm{~Hz}$ & Dó4 & $523,3 \mathrm{~Hz}$ & .000000000000 \\
\hline Dó\#3 & $277,2 \mathrm{~Hz}$ & Dó\#4 & $554,4 \mathrm{~Hz}$ & 00000 \\
\hline Ré3 & $293,7 \mathrm{~Hz}$ & Ré4 & $587,3 \mathrm{~Hz}$ & 000 \\
\hline Ré\#3 & $311,1 \mathrm{~Hz}$ & Ré\#4 & $622,3 \mathrm{~Hz}$ & 0000 \\
\hline $\mathrm{Mi3}$ & $329,6 \mathrm{~Hz}$ & $\mathrm{Mi} 4$ & $659,3 \mathrm{~Hz}$ & 00000000000 \\
\hline Fá3 & $349,2 \mathrm{~Hz}$ & Fá4 & $698,5 \mathrm{~Hz}$ & 00000000000 \\
\hline Fá\#3 & $370,0 \mathrm{~Hz}$ & Fá\#4 & $740,0 \mathrm{~Hz}$ & 00000000000 \\
\hline Sol3 & $392,0 \mathrm{~Hz}$ & Sol4 & $784,0 \mathrm{~Hz}$ & .000000000000 \\
\hline Sol\#3 & $415,3 \mathrm{~Hz}$ & $\mathrm{Sol} \# 4$ & $830,6 \mathrm{~Hz}$ & .000000000000 \\
\hline Lá3 & $440,0 \mathrm{~Hz}$ & Lá4 & $880,0 \mathrm{~Hz}$ & .000000000000 \\
\hline Lá\#3 & $466,2 \mathrm{~Hz}$ & Lá\#4 & $932,3 \mathrm{~Hz}$ & .000000000000 \\
\hline $\mathrm{Si} 3$ & $493,9 \mathrm{~Hz}$ & $\mathrm{Si} 4$ & $987,8 \mathrm{~Hz}$ & 000000000000 \\
\hline
\end{tabular}

Para todas as notas da escala, o flautista repousa seu lábio inferior no bocal, tocando uma de suas arestas. Enquanto isso, o lábio superior é mantido a certa distância da outra aresta do bocal. Um jato de ar deve ser lançado contra a aresta livre de maneira que parte do ar seja direcionada para o interior da flauta, enquanto outra parte é direcionada para fora (Fig. 5). O lábio superior (ajudado pela mandíbula) controla o comprimento e a largura deste jato de ar. Assim, a técnica da embocadura envolve posicionar os lábios e a mandíbula, controlando o vigor do sopro, para obter um som bonito e agradável. 


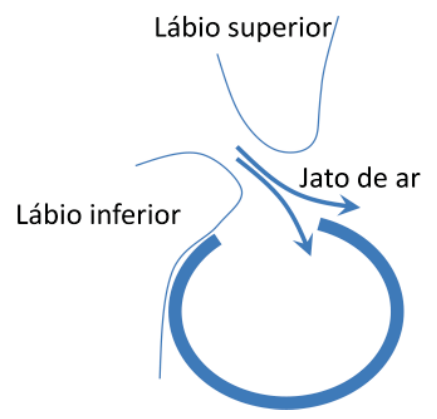

Fig. 5 - Representação esquemática em perfil do posicionamento dos lábios do flautista próximo ao bocal da flauta transversa.

As imagens na Fig. 6 apresentam a embocadura de um flautista iniciante executando as notas Mi3 e Mi4. Como é possível perceber, para executar a nota mais aguda, o flautista deve aproximar seu lábio superior da aresta livre ao mesmo tempo em que contrai os lábios.

Tomando como ponto de partida textos de acústica empregados no ensino de Física superior (HALLIDAY et al., 2009; NUSSENZVEIG, 2004; TIPLER; MOSCA, 2009), não é possível compreender como um flautista consegue passar facilmente de uma oitava a outra, mudando somente a embocadura. Do ponto de vista destes textos, as frequências que surgem em um tubo dependem somente da velocidade do som no ar e de características do tubo (tal como seu comprimento). Como nenhuma destas variáveis é alterada pela embocadura (nem o comprimento efetivo do tubo nem a velocidade do som no ar no interior do tubo), esse controle das oitavas fica sem explicação.
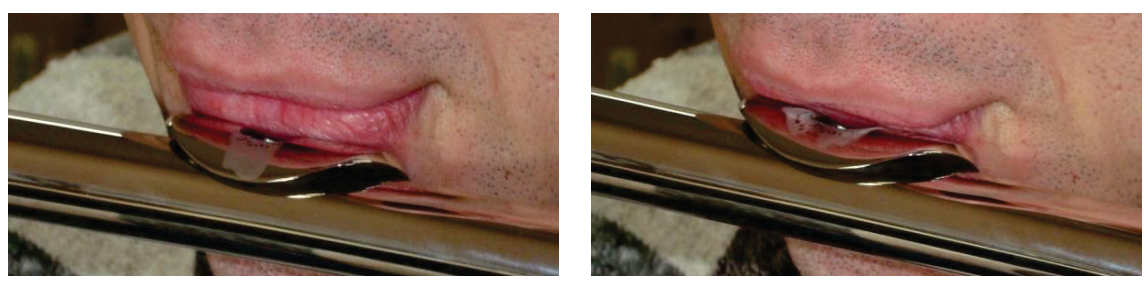

Fig. 6 - Comparação entre a posição dos lábios para produzir as notas Mi3 e Mi4 com a flauta transversa respectivamente. 
Ao longo deste artigo, argumentaremos que essa limitação na compreensão do fenômeno está relacionada ao fato de que sistemas acústicos são abordados no Ensino de Física somente em seus aspectos lineares, quando, a rigor, há processos não-lineares importantes para o entendimento básico do funcionamento dos instrumentos musicais. Como o conceito de linearidade em Física é fundamental para os propósitos deste trabalho, partimos da equação de onda acústica, que é uma equação linear fundamental, destacando seus pressupostos e discutindo seu domínio de validade para, em seguida, tratar a questão da linearidade e da nãolinearidade de fenômenos acústicos.

\section{A equação de onda: uma equação linear}

No estudo de cordas vibrantes, é fácil demonstrar que, para condições relativamente gerais, o movimento da corda deve satisfazer à seguinte equação diferencial (FIGUEIREDO, 1997):

$$
\frac{1}{c^{2}} \frac{\partial^{2} u}{\partial t^{2}}=\frac{\partial^{2} u}{\partial x^{2}}
$$

Qualquer relação que apresente essa forma matemática é chamada equação de onda, e a grandeza representada pela função $u(x, t)$ é uma onda que se propaga ao longo da direção $x$ com velocidade $c$ para a direita ou para a esquerda. No caso das cordas vibrantes, a função $u(x, t)$ representa a distância, ao longo do eixo vertical, de cada ponto da corda até sua posição de equilíbrio em cada instante de tempo conforme a Fig. 7.

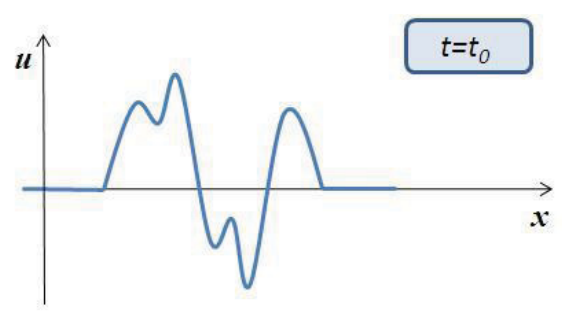

Fig. 7 - Representação de uma perturbação em uma corda.

É importante destacar que qualquer equação do tipo [01] (ou seja, qualquer equação de onda) é sempre linear. Porém, para compreender rigorosamente o significado da linearidade, é preciso definir o seguinte operador: 


$$
L \equiv\left\{\frac{1}{c^{2}} \frac{\partial^{2}}{\partial t^{2}}-\frac{\partial^{2}}{\partial x^{2}}\right\}
$$

Com essa definição, a equação [01] pode ser representada de maneira mais compacta:

$$
L(u)=0
$$

Por definição, a equação [03] será linear se e somente se $L(k \cdot u)=k \cdot L(u)$, em que $k$ é uma constante qualquer, e $L\left(u_{1}+u_{2}\right)=L\left(u_{1}\right)+L\left(u_{2}\right)$, em que $u_{1}$ e $u_{2}$ são funções. Como é possível perceber, o operador $L$ satisfaz as duas condições e a equação de onda pode ser dita linear.

A linearidade da equação de onda traz consigo algumas facilidades importantes para o tratamento matemático e conceitual de fenômenos ondulatórios. É justamente em virtude da linearidade da equação de onda que podemos pensar a superposição de ondas como uma soma direta de duas funções. Em princípio, sempre que duas ondas $u_{1}(x, t)$ e $u_{2}(x, t)$ se encontram em uma região no espaço, consideramos (sem muito questionar) que ocorre uma superposição tal que a onda $u(x, t)$ resultante é igual à soma das ondas componentes $\left(u=u_{1}+u_{2}\right)$ ponto a ponto. A rigor, esta soma direta só pode ser levada a cabo porque a propagação das ondas $u_{1}(x, t)$ e $u_{2}(x, t)$ é governada por uma equação linear. Assim, se $u_{1}(x, t)$ e $u_{2}(x, t)$ satisfazem a equação de onda, sua soma também deve satisfazer à mesma equação, pois $L\left(u_{1}+u_{2}\right)=L\left(u_{1}\right)+L\left(u_{2}\right)$. Se a equação de onda fosse não-linear, não poderíamos tratar a superposição de ondas da mesma maneira.

Com efeito, há ainda mais razões que justificam a preferência dos físicos por uma descrição linear dos fenômenos ondulatórios. Grande parte das equações não-lineares precisa ser resolvida numericamente porque elas nem sempre admitem solução analítica. Outra complicação também muito importante é que, em sistemas descritos por equações não-lineares, pequenas variações nas condições iniciais são mais propensas a produzir estados finais muito diferentes.

Em acústica, dizemos que o som se propaga no ar como uma onda de pressão e que, diferente do que ocorre com cordas vibrantes, o som pode ser considerado uma onda longitudinal. Portanto, devemos ser capazes de escrever uma equação de onda para a propagação do som no ar.

\section{Discussão da equação de onda acústica}

Em apêndice a este artigo, demonstramos formalmente que a equação de onda acústica pode ser deduzida a partir da segunda lei de Newton e das seguintes 
idealizações: (1) A onda acústica produz pequenas perturbações; (2) A onda se propaga sem produzir trocas de calor (propagação adiabática); (3) A viscosidade do fluido em que a onda se propaga pode ser desprezada; (4) A onda acústica não consome nem produz matéria ao se propagar.

Satisfeitas estas condições, é possível afirmar que:

$$
\frac{\rho_{0}}{K_{S}} \frac{\partial^{2} p}{\partial t^{2}}=\frac{\partial^{2} p}{\partial x^{2}}
$$

A equação acima vale para ondas acústicas que se propagam em uma direção. Nela, $K_{S}$ é o módulo de compressibilidade adiabática (CALLEN, 1985), $\rho_{0}$ é a densidade do fluido (ar) quando não há onda se propagando nele e $p$ é a pressão acústica, que resulta da diferença entra a pressão absoluta e a pressão atmosférica avaliadas em um ponto de coordenada $x$ em um instante $t$.

Em primeiro lugar, é possível perceber, ao comparar a equação de onda acústica [04] com a forma geral de uma equação de onda [01], que a velocidade $c$ de propagação do som em um fluido não-viscoso pode ser determinada genericamente por:

$$
c=\sqrt{\frac{K_{S}}{\rho_{0}}}
$$

É preciso chamar atenção, aqui, para o fato de que, mantendo-se todo o resto constante, $a$ velocidade do som no ar diminui com o aumento da densidade do meio. Isso é bastante contraintuitivo, uma vez que, ao comparar a velocidade de propagação do som em gases, líquidos e sólidos, somos levados a acreditar que, em geral, quanto mais denso for o meio, maior será a velocidade de propagação do som neste meio. Entretanto, como é possível perceber na equação [05], embora a relação observada para a densidade do meio e a velocidade do som nesse meio seja verdadeira quando comparamos sólidos, líquidos e gases, a velocidade do som no ar deve diminuir sempre que houver um aumento de densidade que não altere significativamente o módulo de compressibilidade adiabática $K_{S}$.

Se acrescentarmos ao resultado da equação [05] a hipótese de que o ar se comporta aproximadamente como um gás ideal, então o módulo de compressibilidade adiabática pode ser obtido derivando a equação $P V^{\gamma}=P_{0} V_{0}^{\gamma}$ de tal forma que $K_{S}=\gamma P_{0}$. Levando esse resultado, a definição de densidade $\rho_{0}=M_{0} / V_{0}$ e a equação dos gases ideais $P_{0} V_{0}=n R T_{0}$ na equação [05], obtemos:

$$
c=\sqrt{\gamma \frac{P_{0} V_{0}}{M_{0}}}=\sqrt{\gamma \frac{R T_{0}}{M_{\text {molar }}}}
$$


Como é possível perceber da equação [06], quanto maior a temperatura ambiente $T_{0}$, maior será a velocidade do som no ar. A velocidade do som também depende dos gases que compõem o ar. Mantido todo o resto constante, quanto maior for a massa molar média dos gases componentes, menor será a velocidade do som.

Além de analisar a relação da velocidade do som com outras grandezas físicas, a dedução da equação de onda acústica [04] permite discutir sob que condições o som se propaga como uma "onda bem comportada". Dentre os pressupostos adotados, o mais propenso a falhar é o das pequenas variações (e, dentre os princípios evocados, esse é justamente o maior responsável pela linearidade da equação de onda acústica). Em música, a amplitude da onda de pressão é quase sempre muito pequena, se comparada à pressão atmosférica (FEYNMAN, 2008). Portanto, o princípio das pequenas variações geralmente se sustenta. Entretanto, quando da propagação do som produzido por grandes explosões e raios, a equação de onda acústica [04] (e todas as facilidades matemáticas e conceituais que ela traz consigo em virtude da sua linearidade) não pode ser sustentada com a mesma segurança.

No corpo da flauta transversa - a menos de alguns efeitos de borda -, podemos considerar que se propaga uma onda "bem comportada", ou seja, uma onda de pressão que obedece à equação de onda acústica. A equação de onda explica como a onda se propaga, mas não nos informa com respeito ao processo de produção desta onda. Assim, a explicação física da embocadura deve ser diversa daquela que desenvolvemos até o presente momento.

\section{Flauta transversa: um exemplo de instrumento sustentado}

Assim como outros instrumentos de sopro e os instrumentos da família do violino (em contraste com o piano, o violão, o bandolim e outros instrumentos tangidos), a flauta transversa é um instrumento sustentado. O que isso significa? Significa que o som emitido pela flauta pode ser mantido em uma intensidade aproximadamente constante pelo tempo que durar o fôlego do flautista. Isso não ocorre, por exemplo, com o violão, que, tangido uma vez, emite som a intensidades cada vez menores.

Segundo Fletcher (1999), os dispositivos de excitação de instrumentos sustentados são fundamentalmente não-lineares. Nos instrumentos da família do violino, por exemplo, não existe um modelo linear que descreva de maneira satisfatória a transmissão de energia do arco para as cordas. Na flauta, uma nãolinearidade fundamental encontra-se na técnica de sopro e posicionamento dos lábios (a embocadura). 
Na maioria dos instrumentos musicais, é possível distinguir dois tipos de componentes que funcionam de maneira conjunta: excitadores e ressonadores. Diferente do violão e do violino, que possuem mais de um dispositivo ressonador (cordas e caixa, por exemplo), a flauta possui somente um dispositivo ressonador (o tubo, que, controlado pela digitação do flautista, permite produzir as diferentes notas da escala cromática) e um dispositivo excitador (o bocal, que, completado pelos lábios do flautista segundo uma técnica específica de sopro, permite a produção de som). Tais dispositivos podem ser representados esquematicamente como na Fig. 8.

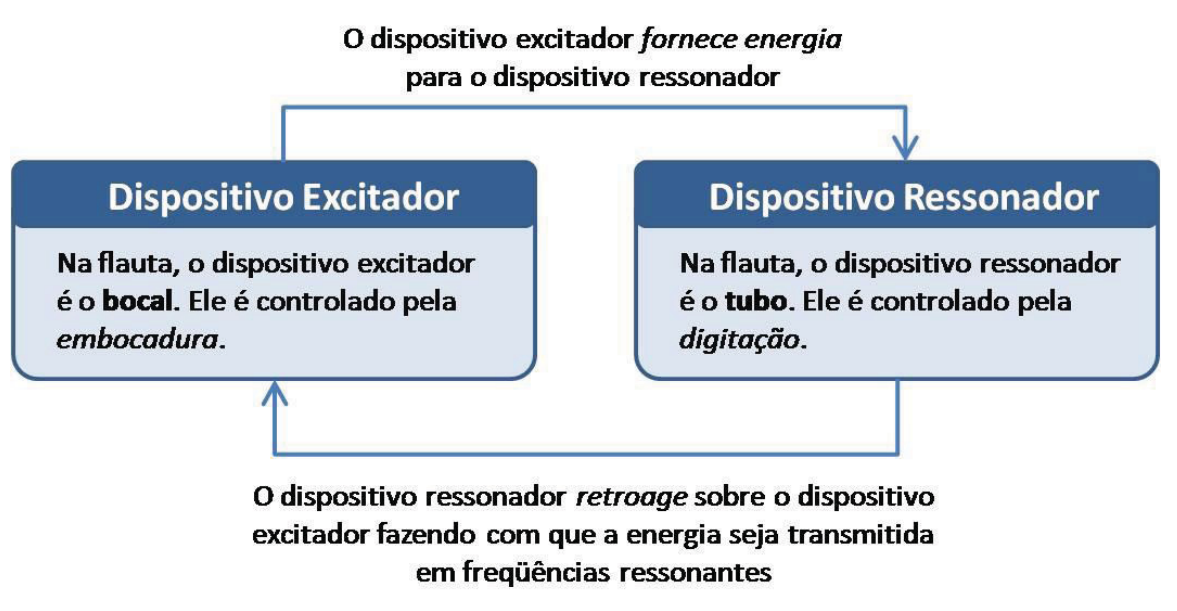

Fig. 8 - Representação esquemática do dispositivo ressonador e do dispositivo excitador em uma flauta transversa, destacando suas relações.

As relações na Fig. 8 sugerem um acoplamento entre os dois dispositivos na medida em que o funcionamento de um não pode ser compreendido corretamente ignorando o funcionamento do outro. Afinal, a ocorrência de ressonâncias no tubo depende da maneira com que o dispositivo excitador é operado pelo flautista (tanto é assim que o flautista pode produzir a mesma nota em oitavas diferentes mudando somente a embocadura). Por outro lado, como será possível perceber a seguir, o funcionamento do dispositivo excitador depende fundamentalmente do comprimento acústico do tubo na medida em que o ar que se movimenta no interior do tubo retroage sobre o bocal determinando as frequências com que entrega energia para o tubo. Dispositivos acústicos que apresentam este tipo de acoplamen- 
to entre ressonador e excitador são também chamados dispositivos auto-excitados (HENRIQUE, 2002).

\section{Excitação da flauta transversa: embocadura e bocal}

Como já foi dito anteriormente, para que seja obtido som da flauta transversa, o flautista deve direcionar um jato de ar contra a aresta livre do bocal de maneira que parte do ar seja direcionada para o interior da flauta, enquanto outra parte é direcionada para fora (Fig. 5). A rigor, o que ocorre no bocal é um movimento muito complexo do jato de ar que sai dos lábios do flautista. Para entender aproximadamente o movimento deste jato de ar, é necessário analisar o movimento do ar no interior do tubo.

Considerando que a equação de onda acústica [04] descreve aproximadamente bem as variações de pressão no interior do tubo e que, nas extremidades abertas, a pressão $P$ é aproximadamente igual à pressão atmosférica $\left(p=P-P_{0}=0\right)$, a pressão acústica $p$ em função do tempo no interior do tubo deve variar de maneira semelhante ao movimento de uma corda de violão, que, fixa nas suas extremidades, movimenta-se segundo seus modos harmônicos de vibração (Fig. 3).

Às variações de pressão acústica correspondem pequenas correntes de ar no interior do tubo. Tais correntes devem satisfazer à condição de que o ar tende a se deslocar das regiões onde a pressão é maior para as regiões em que a pressão é menor. A Fig. 9 representa a pressão acústica $p$ em função da posição $x$ para o segundo harmônico em um tubo duplamente aberto e de comprimento $L$. Como é possível perceber, a pressão acústica se anula nas extremidades. Em consequência disso, a velocidade da corrente de ar deve atingir seu valor máximo nas posições extremas do tubo.
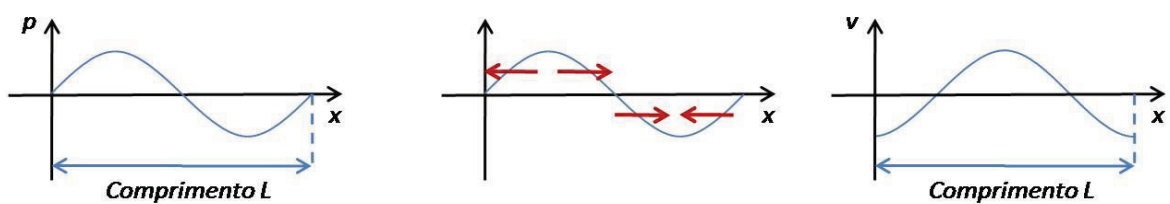

Fig. 9 - Gráficos da pressão acústica e da velocidade das correntes de ar em função da posição para o segundo harmônico no interior de um tubo abertoaberto. 
Este fato de que as condições de contorno para a velocidade em um tubo duplamente aberto são tais que a velocidade do deslocamento da corrente de ar atinge seu máximo nas extremidades do tubo pode ser observado diretamente colocando-se a mão espalmada próxima à abertura da flauta, quando se toca a nota Dó3 ${ }^{3}$ (Fig. 10).

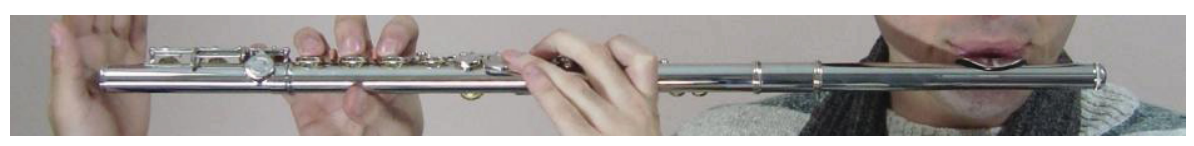

Fig. 10 - Mão se aproximando da extremidade aberta da flauta (oposta ao bocal) enquanto se toca a nota Dó3.

A sensação que se tem, ao colocar a mão próxima à extremidade da flauta, é que, nesta região, o ar vibra em uma frequência característica, dando pequenos "soquinhos" na palma da mão. Este mesmo fenômeno (ainda que mais sutil de se perceber) ocorre próximo aos lábios do flautista. Assim, dando pequenos "soquinhos" no jato de ar que é expelido pelo flautista em direção ao bocal, o ar em movimento no interior do tubo tende a desviar o jato de ar que sai dos lábios do flautista, ora mais para dentro do bocal, ora mais para fora, segundo uma frequência determinada. Essa deflexão periódica do jato de ar contribui, na região do bocal, ora para o aumento da pressão acústica, ora para sua redução. Enfim, é justamente esse acoplamento entre a frequência de oscilação do jato de ar expelido pelo flautista e a coluna de ar em movimento no interior da cavidade ressonante que faz com que o jato de ar forneça energia para a cavidade nas suas próprias frequências ressonantes (FLETCHER, 1974, 1999).

É importante destacar que o acoplamento entre o movimento do jato de ar expelido pelo flautista contra o bocal e a vibração da coluna de ar no interior da flauta está intimamente relacionado a algumas características do jato de ar que devem ser controladas pelo flautista. Assim, a embocadura é justamente a técnica do "sopro correto", ou seja, ela consiste da habilidade (adquirida mediante a prática musical) de se controlarem os parâmetros físicos do jato de ar que são relevantes para o acoplamento desejado entre os movimentos do jato expelido e da coluna

\footnotetext{
${ }^{3}$ Nota mais grave que pode ser obtida com o modelo de flauta transversa que aparece em todas as imagens deste artigo e que corresponde à digitação em que todos os orifícios estão fechados.
} 
de ar. Sem algum domínio mínimo da embocadura, não é possível emitir som agradável com a flauta transversa.

\section{O controle das oitavas e a evidência de não-linearidade}

Flautistas iniciantes são usualmente instruídos a aproximar o lábio superior do bocal, contraí-los e aumentar o vigor do sopro para produzir notas mais agudas (por exemplo, para passar do Mi3 para o Mi4) (Fig. 6). Com efeito, para que o movimento do jato de ar expelido pelo flautista reforce o movimento da coluna de ar dentro da cavidade ressonante e o movimento desta coluna de ar reforce a oscilação periódica do jato de ar, é preciso que exista uma determinada diferença de fase entre esses dois movimentos. Tal diferença de fase está relacionada ao tempo que leva o jato de ar para sair dos lábios do flautista e atingir a aresta do bocal contra o qual este jato é projetado.

Segundo Fletcher (1974), medidas e cálculos mostram que a condição mais eficiente de excitação de uma nota na flauta transversa ocorre quando o tempo de viagem do jato de ar expelido pelo flautista é aproximadamente igual à metade do período de oscilação do ar no interior do tubo. Ou seja, para obter o primeiro Lá da flauta $(440 \mathrm{~Hz})$, é preciso posicionar os lábios e ajustar o vigor do sopro tal que o tempo de viagem $t$ do jato de ar seja aproximadamente igual a $1 / 880 \mathrm{~s}$. Excitando o primeiro harmônico, excitam-se todos os seus múltiplos inteiros.

A rigor, existe alguma flexibilidade na embocadura. Mudando sutilmente a posição dos lábios e o vigor do sopro, o flautista mais experiente deve ser capaz de ajustar não apenas a intensidade, mas o timbre e a afinação do som emitido pelo instrumento. Por isso, as explicações dadas neste artigo valem, ainda, como primeira aproximação ao funcionamento do instrumento e não pretendem dar conta de todos os detalhes envolvidos no uso profissional da flauta transversa.

Enfim, para obter a mesma nota uma oitava acima, o flautista altera a embocadura de maneira a reduzir o tempo de viagem do jato de ar pela metade. Se tal intervalo de tempo for aproximadamente igual a $1 / 1760 \mathrm{~s}$, mantida a mesma digitação do Lá3, o flautista excitará o harmônico $880 \mathrm{~Hz}$ e seus múltiplos inteiros, emitindo, com isso, a nota Lá4.

Retomemos, agora, a questão da não-linearidade. De que maneira essa teoria da embocadura apresentada aqui serve como evidência de que a excitação da flauta transversa é um fenômeno não-linear? Bem, ao tocar a flauta, é possível reconhecer que, aumentando-se o vigor do sopro (até certo limite), obtém-se um som cada vez mais intenso. Essa é, a propósito, a assinatura de fenômenos lineares: quanto mais intensa for a estimulação, tanto mais intenso (proporcionalmente) será 
o resultado. Entretanto, quando o flautista aumenta muito a velocidade do jato de ar expelido contra a aresta do bocal, é possível que o som desapareça (isso corresponde ao desacoplamento entre o jato e a coluna de ar no interior do instrumento) ou que ocorra uma transição para a oitava superior (o que pode ocorrer se o aumento do vigor do sopro implicar a redução pela metade do tempo de viagem do jato de ar). Enfim, como queríamos demonstrar, o dispositivo de excitação da flauta transversa é fundamentalmente não-linear.

\section{Conclusões}

A produção de som com instrumentos musicais constitui um referente fundamental para o ensino de acústica na educação básica e superior. Com efeito, sistemas acústicos são abordados no ensino de Física superior segundo modelos estritamente lineares e o propósito do presente trabalho foi precisamente o de questionar as limitações desses modelos lineares, argumentando que existem processos não-lineares fundamentais que precisam ser levados em consideração para que se compreenda o funcionamento destes instrumentos musicais. Neste artigo, buscamos compreender o funcionamento da flauta transversa a partir de seus princípios físicos, com o objetivo de ilustrar a importância de considerar não-linearidades no estudo do funcionamento de instrumentos musicais.

Tendo feito uma introdução ao funcionamento da flauta transversa e levando em consideração o objetivo de investigar os limites do modelo linear para o funcionamento deste instrumento, deduziu-se a equação de onda acústica e, com ela, uma expressão que permite relacionar a velocidade da onda sonora em um fluido não-viscoso (por exemplo, o ar) às características físicas deste fluido (por exemplo, temperatura, densidade, módulo de compressibilidade adiabática, massa molar). Como a equação de onda acústica é uma equação linear, fenômenos que satisfazem tal equação são, também, fenômenos lineares.

A dedução da equação de onda acústica permitiu tomar conhecimento dos pressupostos que a fundamentam, ou seja, das condições que precisam ser satisfeitas para que a propagação do som possa ser considerada linear no ar. Com efeito, foi possível perceber, a partir da análise desses pressupostos, que a propagação da onda sonora no interior de um tubo (por exemplo, a flauta transversa) deve ser aproximadamente linear, pois são satisfeitos (a menos de alguns efeitos de borda) os pressupostos a partir dos quais foi possível deduzir a equação de onda.

Enfim, apresentando o domínio em que o modelo linear tem sua validade (a propagação do som no interior da flauta), foi possível discutir um processo igualmente fundamental para compreender a emissão de som pela flauta: o funcio- 
namento do seu dispositivo de excitação. Argumentou-se, a partir de resultados de pesquisa em acústica musical, que o dispositivo de excitação da flauta transversa (e de outros instrumentos sustentados, tais como outros de sopro e os da família do violino) são essencialmente não-lineares.

Apresentou-se, aqui, uma teoria predominantemente qualitativa para o funcionamento do dispositivo de excitação da flauta transversa, que é composto pelo bocal da flauta e é completado pelos lábios do flautista. Essa teoria simplificada permitiu explicar, por exemplo, um fato curioso da técnica de sopro e de posicionamento dos lábios na flauta (chamada, pelos músicos, embocadura), em que o flautista, mudando a posição dos lábios e o vigor do sopro, consegue selecionar em que oitava o som será emitido. É importante destacar que tal fato curioso não pode ser explicado pelos modelos acústicos consagrados pelo ensino de Física, que tratam essencialmente de determinar os modos ressonantes em cordas e cavidades, deixando de lado os dispositivos de excitação dos instrumentos musicais. Enfim, esse controle das oitavas é, em si mesmo, uma grande evidência de nãolinearidade no funcionamento da flauta e, sem ele, é impossível compreender fundamentalmente os processos físicos envolvidos da excitação à emissão de som com este instrumento.

\section{Referências}

CALLEN, H. B. Thermodynamics and an introduction to thermostatistics. 2. ed. New York: John Wiley, 1985. 493p.

FEYNMAN, R. P. Lições de física de Feynman. Porto Alegre: Bookman, 2008. 3 $\mathrm{v}$.

FIGUEIREDO, D. G. Análise de Fourier e equações diferenciais parciais. 3. ed. Rio de Janeiro: Instituto de Matemática Pura e Aplicada, 1997. 274 p.

FLETCHER, N. H. The nonlinear physics of musical instruments. Reports on Progress in Physics, v. 62, p. 723-764, 1999.

FLETCHER, N. H. Some acoustical principles of flute technique. The Instrumentalist, v. 28, n. 7, p. 57-61, 1974.

GALlAVOTTI, G. Foundations of fluid dynamics. New York: Springer, 2002. $513 \mathrm{p}$. 
HALLIDAY, D.; RESNICK, R.; WALKER, J. Fundamentos de física, volume 2: Gravitação, ondas e termodinâmica. Rio de Janeiro: LTC, 2009. 295 p.

HENRIQUE, L. Acústica musical. Lisboa: Calouste Gulbenkian, 2002. 1130 p.

NUSSENZVEIG, H. M. Curso de física básica, volume 2: Fluidos, oscilações e ondas, calor. São Paulo: Edgard Blucher, 2004. 314 p.

TIPLER, P. A.; MOSCA, G. Física para cientistas e engenheiros, volume 1: Mecânica, oscilações e ondas, termodinâmica. Rio de Janeiro: LTC, 2009. 759 p.

\section{APÊNDICE: Um caminho para deduzir a equação de onda acústica}

A dinâmica dos fluidos é governada pela equação de Navier-Stokes (GALLAVOTTI, 2002), que, derivada da $2^{\text {a }}$ lei de Newton, tem status de lei geral e é necessária para deduzir a equação de onda acústica. Assim, deduzimos, em primeiro lugar neste apêndice, a equação de Navier-Stokes para um fluido nãoviscoso sujeito somente à força que resulta das variações da pressão no seu interior. Em seguida, passamos à dedução da equação de onda acústica, destacando seus pressupostos/idealizações fundamentais.

\section{A equação de Navier-Stokes}

Considere uma região do espaço que, preenchida por um fluido (por exemplo, ar), possa ser dividida em pequenas porções, que serão chamadas volumes de controle. Os volumes de controle podem ser imaginados como pequenas caixinhas imateriais fixas no espaço que são atravessadas constantemente pelo fluido em movimento e que podem ser quase tão pequenas quanto se queira (Fig. 11).

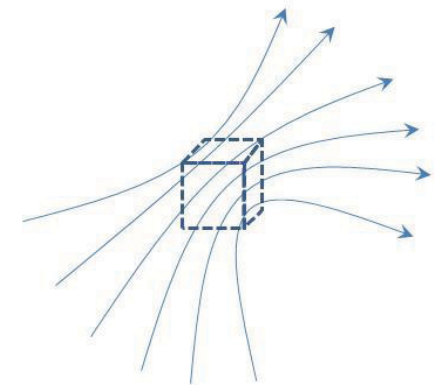

Fig. 11 - Representação de um fluido que, em movimento, atravessa um volume de controle. 
Em mecânica de corpos rígidos, podemos imaginar que cada partícula que constitui o corpo possui uma velocidade própria em cada instante de tempo e que a $2^{\mathrm{a}}$ lei de Newton determina a taxa de variação desta velocidade em função da resultante das forças aplicadas. Em mecânica de fluidos, isso também pode ser feito, mas é mais intuitivo não pensar no movimento individual de cada "partícula" do fluido. Pelo contrário, atribuímos a cada volume de controle uma velocidade. O que isso significa? Significa que, ao passar por cada volume de controle, a velocidade da "partícula" de fluido é igual à velocidade atribuída a este volume de controle. Observe que não são os volumes de controle que se movimentam, mas as "partículas" de fluido que passam por eles.

Considere, agora, uma porção tão pequena de fluido que possa ser considerada uma "partícula" de massa $M$. Podemos escrever a $2^{\mathrm{a}}$ lei de Newton para esta partícula:

$$
\vec{F}_{R E S}=M \frac{d \vec{v}_{p}}{d t} .
$$

A maneira newtoniana de tratar o movimento não favorece muito o estudo da dinâmica de fluidos, pois a segunda lei de Newton vale para cada "partícula" do fluido. Precisamos escrever a $2^{\mathrm{a}}$ lei de maneira a substituir a taxa de variação da velocidade da "partícula" $\vec{v}_{p}$ pelas taxas de variação das velocidades dos diversos volumes de controle.

Como a velocidade de cada partícula (dada sua localização no espaço e no tempo) é igual à velocidade atribuída ao volume de controle, podemos escrever:

$$
\vec{v}_{p}=\vec{v}(\vec{r}, t)
$$

Nessa equação, $v(x, t)$ é a velocidade no tempo $t$ atribuída ao volume de controle situado na posição $r$. Pela regra da cadeia:

$$
\begin{aligned}
\frac{d \vec{v}_{p}}{d t} & =\frac{\partial \vec{v}}{\partial t}+\frac{d x}{d t} \frac{\partial \vec{v}}{\partial x}+\frac{d y}{d t} \frac{\partial \vec{v}}{\partial y}+\frac{d z}{d t} \frac{\partial \vec{v}}{\partial z} \\
& =\frac{\partial \vec{v}}{\partial t}+\vec{v} \cdot \nabla \vec{v} .
\end{aligned}
$$

Substituindo a equação [09] na equação [07] e dividindo o resultado pelo volume, obtemos:

$$
\vec{f}_{R E S}=\rho\left(\frac{\partial \vec{v}}{\partial t}+\vec{v} \cdot \nabla \vec{v}\right)
$$

Nessa equação, $\vec{f}_{R E S}$ é a densidade de força resultante ponto a ponto e $\rho$ é a densidade do fluido avaliada no volume de controle. Essa equação deve ser satisfeita pelo fluido em cada posição do espaço. Como é possível perceber, essa equa- 
ção é não-linear para a velocidade, pois envolve um termo que depende do produto entre o vetor velocidade e as derivadas deste vetor: $\vec{v} \cdot \nabla \vec{v}$.

A densidade de força resultante $\vec{f}_{R E S}$ pode envolver forças de diversas naturezas. Como estamos interessados em obter a equação de Navier-Stokes para o caso mais específico em que a única força exercida no fluido é devida às variações de pressão no interior do próprio fluido, é possível demonstrar que $f_{R E S}=-\nabla P$ em que $P$ é a pressão em cada ponto do fluido. Com isso, a equação de NavierStokes resulta:

$$
-\nabla P=\rho\left(\frac{\partial \vec{v}}{\partial t}+\vec{v} \cdot \nabla \vec{v}\right)
$$

\section{A equação de onda acústica}

A seguir, vamos demonstrar que, para deduzir a equação de onda acústica, é suficiente fazer as seguintes idealizações:

(1) O som se propaga no ar como uma onda de pressão em que a pressão varia sutilmente em torno da pressão atmosférica (condição de pequenas variações);

(2) $\mathrm{O}$ ar sofre expansões e compressões adiabáticas quando da propagação do som (condição de transformações adiabáticas);

(3) $\mathrm{O}$ ar não tem viscosidade e a única força que põe as pequenas porções de ar em movimento se deve ao gradiente de pressão (condição da resultante das forças);

(4) O ar não desaparece nem surge simplesmente; ele é sempre transportado de tal maneira que todo o aumento ou a diminuição da densidade do ar em cada região do espaço se deve ao fluxo de ar nas fronteiras dessa região (condição de continuidade).

Essas quatro idealizações, aliadas à equação de Navier-Stokes, permitem enunciar uma equação de onda que representa a propagação do som no ar em uma dimensão (FEYNMAN, 2008).

Considere que, quando da propagação da onda de som, a pressão e a densidade do meio (ar) variam sutilmente em torno da densidade e pressão atmosféricas ( $\rho_{0}$ e $P_{0}$, respectivamente). Para transformações adiabáticas, satisfeita também a condição de pequenas variações, o módulo de compressibilidade adiabática $K_{S}$ (CALLEN, 1985) permite estimar a relação entre as variações de pressão e variação de densidade: 


$$
K_{S} \equiv \rho_{0}\left(\frac{\partial P}{\partial \rho}\right)_{S} \cong \frac{\rho_{0}}{\rho-\rho_{0}}\left(P-P_{0}\right) .
$$

Definindo a razão $\delta \equiv\left(\rho-\rho_{0}\right) / \rho_{0}$ e a pressão acústica $p \equiv P-P_{0}$, obtém-se a relação:

$$
p=K_{S} \delta .
$$

Observe que a condição da resultante das forças já está incorporada à dedução da equação simplificada de Navier-Stokes feita na seção anterior. Reduzindo a equação [11] à dimensão $x$ e desprezando termos de ordem superior, obtemos:

$$
\frac{\partial p}{\partial x}+\rho_{0} \frac{\partial v}{\partial t}=0 .
$$

Da condição de continuidade aplicada à dimensão $x$, desprezando termos de ordem superior e aplicando a definição de $\delta$, obtemos:

$$
\frac{\partial \delta}{\partial t}+\frac{\partial v}{\partial x}=0 .
$$

Enfim, derivamos a equação [14] em $x$, a equação [15] em $t$ e combinamos os resultados com a equação [13] para obter a equação de onda acústica:

$$
\frac{\rho_{0}}{K_{S}} \frac{\partial^{2} p}{\partial t^{2}}=\frac{\partial^{2} p}{\partial x^{2}} .
$$

